\title{
Job satisfaction, work engagement, and turnover intention of CTE health science teachers
}

\author{
Kathleen A. Park ${ }^{1}$ and Karen R. Johnson ${ }^{\star 2}$ \\ ${ }^{1}$ Austin Community College, Medical Laboratory Technology/Phlebotomy Program, Health \\ Science Division, 4400 College Park Drive, Round Rock, Texas 78865, USA \\ ${ }^{2}$ University of North Texas, Department of Learning Technologies, 3940 North Elm Street, \\ G180, Denton, Texas 76207-7102, USA
}

Received: 21.03.2019, Accepted: 26.09.2019, Published: 19.12.2019

\begin{abstract}
Context: The healthcare profession is one of the largest growing occupations in the United States (US). Yet, there is a shortage of healthcare professionals and the situation is further compounded by insufficient instructors to prepare individuals to provide safe and quality care. A number of teachers leave the profession within 3 years of work in the classroom. The deficiency of health science teachers will negatively influence the workforce needs of the health sector. Addressing the issue of turnover of career and technical education (CTE) health science teachers is particularly important not only to respond to the chronic teacher shortage but also the deficit of healthcare professionals. It is important to ensure that teachers are satisfied and engaged at work because of the positive impact these job attitudes contribute to performance. Considering the importance of CTE health science teachers to the health sector, there is need to examine teacher job satisfaction and work engagement and the impact this may have on turnover intention. The purpose of this study is to examine the relationships between job satisfaction, work engagement, and turnover intention of health science teachers in the US.
\end{abstract}

Approach: In this study, hierarchical multiple regression was used to analyze a total of 249 responses from CTE health science teachers in the State of Texas in the US.

*Corresponding author: Karen.Johnson@unt.edu 
Findings: The results showed positive correlations between job satisfaction and work engagement. Additionally, job satisfaction and work engagement were negatively correlated with turnover intention. The findings also indicated that work engagement did not moderate the relationship between job satisfaction and turnover intention.

Conclusions: This study builds on the work of previous researchers by further supporting the links between job satisfaction, work engagement, and turnover intention specifically in the context of teachers in CTE health science. Leaders in academic settings play a role in ensuring that strategies are in place to satisfy and engage teachers as practical ways to reduce turnover intention. In particular, administrative leaders should recognize teachers' contributions, provide development opportunities, and promote challenging responsibilities and autonomy within the classroom. It is critical to have adequate and qualified teachers to prepare individuals to deliver safe and quality healthcare.

Keywords: Job satisfaction, work engagement, turnover intention, CTE, health science teachers, vocational education and training, VET

\section{Job Satisfaction, Work Engagement, and Turnover Intention of Health Science Teachers}

The healthcare profession is one of the largest growing occupations in the United States (US) (US Bureau of Labor Statistics, [BLS], 2015). Of the top 20 fastest growing job categories, 11 fit into the healthcare field. Nationwide, the job growth outlook for healthcare professionals is projected to be on average 34\% between 2014 and 2024 (BLS, 2015). Despite the growing healthcare job category projections, there is a shortage of healthcare professionals in the US (Rowe, Fulmer, \& Fried, 2016). The national average of physicians to Americans is 2.3 to 1,000 putting a strain on the healthcare professional population (Texas Medical Association, 2016). However, a deficiency of instructors has been noted as one of the primary reasons thousands of applicants are denied admission to pursue health related careers (American Association of Colleges of Nursing, 2015) despite the projected high job growth over the 20122022 decade (BLS, 2013). With an aging population, the need for excellent care management increases and healthcare professionals play a major role in delivering safe and quality care (Snavely, 2016). The imbalance of supply and demand will negatively affect the healthcare system and more broadly the health of the nation's economy. Therefore, it is critical to have adequate and highly trained healthcare professionals (Snavely, 2016). However, in several US States, there is a chronic health science teacher shortage affecting both secondary and postsecondary education. More specifically, there is a demand for Career and Technical Education (CTE) health science teachers. In the US, the Carl D. Perkins Act of 1984 was the first 
of four legislative Acts passed to support vocational education, now called CTE (Dougherty \& Lombardi, 2016).

CTE is the practice of teaching specific career skills to students in middle schools, high schools, and post-secondary institutions. CTE prepares both youth and adults for a wide range of early careers and more advanced educational opportunities (Advance CTE, 2017) and also aids in preparing individuals to teach in numerous occupations including health-related careers. Some of the certifications students may earn in the CTE healthcare professions include certified nurse aide, clinical medical assistant and patient care technician, pharmacy technician, emergency medical technician, dental assistant, and phlebotomy (Texas Education Agency [TEA], 2017). These professions are foundational to more advanced healthcare professions. Although part of the vision of CTE leaders includes the recruitment of health science teachers to help alleviate the shortage of healthcare professionals by increasing interest at the secondary education level in the US (Advance CTE, 2017), if not addressed soon, this deficiency of health science teachers will negatively influence the workforce needs of the health sector.

In general, approximately $25 \%$ of new teachers in the US leave the teaching profession before the third year on the job (Skaalvik \& Skaalvik, 2011). Many teachers in CTE related areas leave the teaching profession for a variety of reasons (Ruhland \& Bremer, 2003; Walter \& Gray, 2002; Song, Martens, McCharen, \& Ausburn, 2011), such as, job dissatisfaction, career dissatisfaction, available opportunities, or job performance (Rhodes \& Doering, 1983). Job satisfaction is one of the most studied topics in organizational psychology (Judge, Weiss, Kammeyer-Mueller, \& Hulin, 2017) because of its positive impact on job performance in general and turnover intentions (Skaalvik \& Skaalvik, 2011). Job satisfaction pertains to how an individual evaluates his/her present job conditions (Judge \& Kammeyer-Mueller, 2012). Research shows that satisfied individuals are likely to be more engaged at work resulting in increased organizational outcomes (Harter, Schmidt, \& Hayes, 2002). In the human resource management and development literature, engaged employees are described as energetic, proactive, produce quality work, effectively handle difficult job situations (Schaufeli, Bakker, \& Salanova, 2006) and are less likely to leave the job (Hakanen, Bakker, \& Schuafeli, 2006). We feel that teachers who are engaged can be described as having the same attributes.

In today's competitive work environment, it is important to ensure that teachers are satisfied and engaged at work because of the level of dedication and value provided to the success of students and schools. Few studies have been done on the turnover intention and retention of secondary CTE health science teachers. Ideas have been investigated on ways to retain teachers through such programs as teacher mentoring; however, the factors influencing teachers' intention to leave the profession needs further investigation (Ruhland, 2001). Considering the importance of CTE health science teachers to the health sector workforce, there is a need to examine job satisfaction and work engagement and the impact this may 
have on turnover intention. While job satisfaction, work engagement, and turnover intention have been studied extensively, these variables have not been examined together in the context of CTE health science teachers despite high teacher attrition rates and the significance of satisfied and engaged employees. This study will address a gap in the literature and provide insight to academic leaders/administrators and decision makers in managing the educational setting. The purpose of the study is to investigate the relationships between job satisfaction, work engagement, and turnover intention of CTE health science teachers. The study addressed the following research questions:

1. What are the relationships between job satisfaction, work engagement, and turnover intention of health science teachers?

2. Does work engagement moderate the relationship between job satisfaction and turnover intention?

The results of the study may influence retention of health science teachers in CTE. This teacher shortage will have an impact on the future labor market projections for healthcare professionals and the health of the society. In the following sections, details are provided on the theoretical framework and a review of literature on job satisfaction, work engagement, and turnover intention.

\section{Theoretical Framework}

Herzberg Motivation/Hygiene Theory. Herzberg (1971) proposed a two-factor theory, called the Motivation-Hygiene Theory (Herzberg, Mausner, \& Synderman, 1993). The theory posited that humans have two different types of needs and different aspects of the work environment either satisfies or dissatisfies those needs. The theory includes factors for motivation and hygiene (Herzberg et al., 1993).

Motivation factors (intrinsic). Certain characteristics, called motivators, are important for employees' level of job satisfaction (Waltman, Bergon, Hollenshead, Miller, \& August, 2012). The motivation factors are fundamental to the job and are intrinsically rewarding for individuals (Herzberg, 1971; Herzberg et al., 1993). For example, tasks well done, advancement, recognition of achievement, job responsibility, or the work itself are considered to be intrinsically rewarding (Herzberg, 1971; Sharp, 2008). Therefore, motivation is based on a sense of achievement and personal growth (Herzberg, 1971). When these factors are satisfying to the individual, the factors then work as motivators for the individual (Herzberg, et al., 1993). However, the factors do not cause dissatisfaction if they are missing in the workplace; instead, there is a lack of satisfaction for the individual (Herzberg, 1971; Herzberg et al., 1993). 
Hygiene factors (extrinsic). Other characteristics, known as hygiene factors, lead towards an employee's job satisfaction (Waltman, et al., 2012). The hygiene factors, also known as extrinsic factors, are important for individuals basic survival needs (Herzberg 1971; Herzberg, et al., 1993). These factors include salary, rewards, benefits, proficient supervision, competent administration, a good work environment, and work relationships (Herzberg, 1971; Herzberg et al., 1993; Bassett-Jones \& Lloyd, 2005; Sharp, 2008). If these factors are not satisfied then the individual becomes dissatisfied (Herzberg et al., 1993). Even if these factors are not met for the worker, they do not motivate an individual but help to prevent dissatisfaction (Herzberg et al., 1993). Herzberg's theory implies that satisfaction and dissatisfaction are opposite of the other and that job satisfaction is an absence of job dissatisfaction (Herzberg, et al., 1993). An individual's attitude or behavior is based on the needs, motives, and values to be satisfied (Muller, Alliata, \& Benninghoff, 2009). This theory has been applied to teachers in educational settings (Nias, 1981).

The Herzberg motivation-hygiene theory offers an explanation for the relationships between job satisfaction, work engagement, and turnover intention. Teachers may have the intent to leave the job due to a lack of motivation and not being satisfied in the workplace. For example, if the hygiene factors are not present, it will be challenging for teachers to perform the daily tasks of instruction, and the teacher may become dissatisfied with the job. Without these factors, teachers' levels of work engagement may decrease due to lack of satisfaction that could possibly contribute to the intent to leave the teaching profession. It is important to note that, according to some researchers (Lindsay, Marks, \& Gorlow, 1967), the concept of satisfaction cannot be evaluated only on the basis of two components. However, in spite of ambiguity, Herzberg motivation-hygiene theory has informed numerous studies over the years and is still viewed as "the basis for sound managerial principles" (Sachau, 2007, p. 390).

\section{Literature Review}

\subsection{Job Satisfaction}

Job satisfaction is defined as a ". . a pleasurable or positive emotional state resulting from the appraisal of one's job or job experiences" (Locke, 1976, p. 1304). Individuals experience increase in job satisfaction when their needs are met in the workplace (Locke, 1976). Job satisfaction can be influenced by job characteristics (Oldham, Hackman, \& Pearce, 1976). Five job characteristics proposed as influencers on job satisfaction are: identity of the task, significance of the task, the variety of skills needed for the task, autonomy, and feedback about the task completed (Oldham et al., 1976). Some researchers have emphasized that job satisfaction is derived not so much from the climate of the work environment but more so 
from the basic duties assigned including the challenges of the responsibilities and the positive feelings derived from performing work functions (Tietjen \& Myers, 1998).

Various aspects of a job that affect job satisfaction can be grouped into two categories: intrinsic and extrinsic. Intrinsic job satisfaction pertains to the work tasks or job content such as variety, skill utilization, and autonomy, while extrinsic satisfaction is derived from working conditions, pay, and supervisor and peer support (Spector, 1997). When individuals are dissatisfied, tendencies toward absenteeism, lack of energy, and lack of regard for one's own work increase within the organization (Bakker, Demerouti, \& Euwema, 2005). Research indicates that job satisfaction is an antecedent of employee engagement (Abraham, 2012). A lack of job satisfaction and emotional exhaustion leads to increased intention to leave the organization (Skaalvik \& Skaalvik, 2011).

\subsection{Work Engagement}

Work engagement is defined as "a positive, fulfilling, work-related state of mind that is characterized by vigor, dedication, and absorption" (Schaufeli \& Bakker, 2004, p. 295). Vigor describes the individual's willingness to invest in work and persist in that work, even when it is very difficult. Dedication is how involved, enthusiastic, and inspired the individual is by the job performed. Absorption means the employee is so immersed in the job that time becomes distorted (Schaufeli \& Bakker, 2004) and the individual has a hard time leaving work because of the absolute enjoyment gained (Schaufeli, Salanova, González-Romá, \& Bakker, 2002).

Khan (1990), the first to develop thoughts on the concept, found that when individuals are engaged at work their cognitive, emotional, and physical selves are reflected in their job performance and are less likely to leave the organization. Work engagement has become significant for practitioners and researchers because of its significant influence on organizational outcomes (Kim, 2017), including increased individual productivity and commitment, a decrease in recruitment and retention costs; and organizational stability (Harter et al., 2002; Saks, 2006; Saks \& Gruman, 2014; Schaufeli et al., 2002; Schaufeli \& Bakker, 2004). Workplace factors, such as learning activities and strong support, have been found to predict work engagement in higher vocational education (Nagele, Neuenschwander, \& Rodcharoen, 2018). Work engagement is beneficial to the organization and the employee, both at work and outside of work (Seppälä, Mauno, Feldt, Hakanen, Kinnunen, Tolvanen, \& Schaufeli, 2009). Work engagement has been found to be a predictor of turnover intention and an antecedent (Abraham, 2012) and outcome of job satisfaction (Yalabik, Rayton, \& Rapti, 2017); therefore emphasizing the need for supervisor support, fair and sound company policies and procedures, and a job that is challenging is important (Abraham, 2012). Engaged individuals are immersed in their work roles and are less likely to leave the job (Khan, 1990). Because of the 
potential outcomes associated with engaged workers, teachers should strive for this desired state especially in view of the intricate and complex nature of jobs in the health sector.

\subsection{Turnover Intention}

Over the years, turnover intention has been studied by researchers because of its important effect on productivity. Ingersoll (2001) defined turnover intention, as the likelihood an employee would voluntarily leave the organization. Job satisfaction (Mobley, 1982), organizational commitment (Reio \& Segredo, 2013) and administrative leadership (Thibodeaux, Labat, Lee, \& Labat, 2015) have been found to be significant predictors of turnover intention. A dissatisfied employee has the tendency to evaluate the cost of quitting and searching for alternative jobs (Mobley, 1982). To find a new job means starting over and could involve significant risks that a worker might be hesitant to take (Halbesleben \& Wheeler, 2008). Reio and Segredo (2013) found that workers who adapted well to the work environment, connecting with mentors, were more committed to the organization; this resulted in decreased intent to leave the profession.

Teacher turnover affects students and the school districts; training and replacing teachers can be very costly. Even seasoned tenured teachers have the desire to leave the profession if the teacher experiences job dissatisfaction (Ingersoll, 2001). Ingersoll (2001) further pointed out that "popular education initiatives, such as teacher recruitment programs, will not solve staffing problems of schools if they do not address the organizational sources of low retention" ( $p$. 499). One of the major reasons for teacher turnover is organizational conditions (Ingersoll, 2001). Because research reveals that teachers have the tendency to leave the job after three years of teaching (Skaalvik \& Skaalvik, 2011), job satisfaction is investigated in this study since it is a highly salient antecedent of turnover and turnover intention (Lambert, Lynne Hogan, \& Barton, 2001). Having an engaged workforce should be top priority in all organizations because an engaged employee may find it difficult to leave work since they would have invested high energy in the job and a feeling of work pride and aspiration resulting in strong work performance (Schaufeli \& Salanova, 2007). The shortage of CTE health science teachers coupled with the projected growth of health-related job positions warrants a need to investigate job satisfaction, teacher engagement, and turnover intention. Based on review of the literature, the following hypotheses were formed:

H1. Job satisfaction will be positively related to work engagement.

H2. Job satisfaction will be negatively related to turnover intention.

H3. Work engagement will be negatively related to turnover intention.

H4. Work engagement will moderate the link between job satisfaction and turnover intention. 


\subsection{Research Method}

The target population for the study consisted of full time health science teachers in CTE in the US. The sample of the population included health science teachers in the state of Texas. As the second largest state with an estimated population at 28 million (US Census Bureau, 2017), a projected population of 45 million by 2040 from the Texas State Data Center, and more than 5.7 million baby boomers who are eligible for Medicare, there is increasing strain on the healthcare professional population (Texas Medical Association, 2014). The study sample consisted of current full-time health science teachers in public secondary independent school districts across the state of Texas with at least one year health science teaching experience and at least two years of work experience in a healthcare profession previously to teaching in this area, with an associate or bachelor's degree within the field. This information was provided by a public information request from the Texas Education Agency. The list of health science teachers was from the 2017-2018 school year.

The data were collected through a computer-based questionnaire using the web-based software, Qualtrics. The teachers currently listed as full-time with the Texas Education Agency received a letter explaining the importance of the survey and invitation to participate. This was followed by invitation emails. Of the 900 emails sent to independent school districts in Texas, 250 respondents completed the survey, resulting in a response rate of $27.8 \%$. After deleting one unusable survey, 249 were analyzed for this study. The majority of respondents were females (89.6\%). Most respondents were 45-54 years of age (37.6\%) or 35-44 years $(29.6 \%)$. The majority of respondents held a bachelor's (40\%) or master's (34\%) degree. Almost $30 \%$ of respondents had one to three years teaching experience with $22 \%$ having four to six years of experience.

The variables for this study were job satisfaction, work engagement, and turnover intention. All items on the questionnaire were adapted from previously existing scales. Weiss, Dawis, and England (1967) developed the Minnesota Satisfaction Questionnaire (MSQ) to survey individuals on their overall feeling of the job. Used for this study was the short form of the MSQ containing 20 questions with three subscales: 1) intrinsic satisfaction, 2) extrinsic satisfaction, and general satisfaction (Weiss et al., 1967). The 20 questions combined measure general job satisfaction. However, the intrinsic and extrinsic subscales were used for this study with 12 items measuring intrinsic satisfaction and 6 items measuring extrinsic satisfaction. The survey is designed with a five-point Likert Scale, ranging from 1 (not satisfied) to 5 (extremely satisfied). Sample items of intrinsic and extrinsic satisfaction are, respectively, "the feeling of accomplishment I get from the job" and "my pay and the amount of work I do". The shortened MSQ has been used in previous studies with Cronbach's alpha of 0.90 (Hancer \& George, 2003).

Utrecht Work Engagement Scale (UWES) was used to measure work engagement (Schaufeli et al., 2006). The shortened nine-item survey UWES-9 with three subscales (vigor, de- 
dication, and absorption) was used for this study. Work engagement has been examined as both one-dimensional or three-dimensional construct (Seppälä, et al., 2009). The three subscales were measured using three items each. The UWES-9 is measured on a seven-point scale, with "never" as (0) and "always" as (6). A sample item is "when I get up in the morning, I feel like going to work". The reliability of the nine-item scale was 0.92 in the original study (Schaufeli et al., 2006).

The Michigan Organizational Assessment Questionnaire (MAOQ) that includes a turnover intention subscale was used in this study to measure turnover intention (Camman, Fichman, Jenkins, \& Klesh, 1979). The three-item subscale was designed to investigate the psychological state of the participants related to the issues regarding life at work (Reio \& Segredo, 2013) and is measured on a Likert seven-point scale with responses ranging from 1 (strongly disagree) to 7 (strongly agree) (Camman et al., 1979). The sub-scale has been used in several studies over the last several decades and has a Cronbach's alpha value of up to 0.88 (Abraham, 1999).

\subsection{Results}

Various techniques were used to analyze the data to answer the research questions. Reported in this section are the descriptive statistics, (including mean and standard deviation), correlations, reliability and construct validity and results from hierarchical multiple regression analyses.

In Table 1, the mean, standard deviation, and bivariate correlations among all variables in the study are presented. As shown in Table 1, intrinsic and extrinsic job satisfaction and all three subscales of work engagement were positively correlated. The relationship among these variables ranged from $\mathrm{r}=0.284$ to 0.818 . For example, work engagement (vigor) was significantly and positively associated with intrinsic job satisfaction $(\mathrm{r}=0.690)$. Although both intrinsic and extrinsic job satisfaction are positively related to work engagement, overall, the relationship between intrinsic job satisfaction and work engagement was stronger than the relationship between extrinsic job satisfaction and work engagement. This means, teachers are more motivated and therefore intrinsically satisfied with recognition of achievement, job responsibility/autonomy, and the work itself. 
Table 1: Simple Correlation Matrix for all Variables

\begin{tabular}{lcccccccc}
\hline \multicolumn{1}{c}{ Variable } & Mean & SD & 1 & 2 & 3 & 4 & 5 & 6 \\
1. Job Satisfaction-Intrinsic & 4.04 & 0.65 & - & & & & & \\
2. Job Satisfaction-Extrinsic & 3.12 & 0.93 & $.690^{* *}$ & - & & & & \\
3. Work Engagement-Vigor & 5.18 & 1.25 & $.603^{* *}$ & $.500^{* *}$ & - & & & \\
4. Work Engagement-Dedication & 5.74 & 1.07 & $.535^{* *}$ & $.426^{* *}$ & $.818^{* *}$ & - & & \\
5. Work Engagement-Absorption & 5.69 & 1.02 & $.442^{* *}$ & $.284^{* *}$ & $.678^{* *}$ & $.744^{* *}$ & - & \\
6. Turnover Intention & 1.93 & 1.93 & $-.529^{* *}$ & $-.452^{* *}$ & $-.452^{* *}$ & $-.452^{* *}$ & $-.295^{* *}$ & - \\
Note. ${ }^{* *}$ Correlation is significant at the 0.01 level (2-tailed). & & & & & & \\
\hline
\end{tabular}

Job satisfaction and work engagement negatively correlated with turnover intention. The relationship among these variables varied from $r=-0.295$ to -0.617 . For example, turnover intention negatively correlated with extrinsic job satisfaction $(\mathrm{r}=-0.617)$. The teacher who is absorbed $(r=-.295)$ in his/her work will be least likely to leave the job. The absorbed teacher is so involved at work and will lose track of time. Overall, the Pearson correlation coefficient values indicated that as job satisfaction and work engagement increases, turnover intention decreases. These results supported hypotheses 1, 2, and 3.

Cronbach's alpha was calculated to determine reliability for all scales. The reliability scores for all the scales were within the acceptable range in comparison to previous studies and as recommended by Nunnally and Bernstein (1994). Cronbach's alpha values for this study ranged from 0.775 to 0.933 .

Confirmatory factor analysis (CFA) was used to confirm the factor structure of the scales. Each of the constructs used in the study was validated in previous research. The output from CFA suggested that the model for this study was a reasonable fit with the a priori factor structure $\chi 2 / \mathrm{df}$ acceptable at 3.62 (Hooper, Coughlan, \& Mullen, 2008), Tucker Lewis Index (TLI) also acceptable at 0.796 (Cangur \& Ercan, 2015) and root mean square error of approximation (RMSEA) at 0.10. RMSEA between 0.80 and 0.10 is considered neither a good or bad fit (Cangur \& Ercan, 2015).

When conducting multiple regression analysis, certain assumptions should be met to promote the validity of the results. Multicollinearity is a problem when predictor variables correlate at a level greater than 0.80 (Keith, 2015). The correlation matrix in Table 1 shows a slightly high correlation between the work engagement subscales, vigor and dedication (0.818). Collinearity diagnostics were also done. A variance inflation factor (VIF) of more than 10 indicates that multicollinearity may exist (Keith, 2015). However, the VIF results for the collinearity statistics in this study were less than 10. Delete 'therefore, multicollinearity did not occur. Outliers were evaluated using Cook's distance method in SPSS. The results obtained found one outlier that did not affect the results of the regression analysis since the 
difference in R-squared change was 0.001 . The assumption of normality was met because the residuals approximated a normal curve.

Hierarchical multiple regression analysis was used to determine the effect of job satisfaction and work engagement on turnover intention. Job satisfaction was first entered in the model, followed by work engagement. When conducting hierarchical regression, all variables are entered into the model in the order supported by previous research. Work engagement is affected by employees who are satisfied with their job (Abraham, 2012; Skaalvik \& Skaakvik, 2014).

The model summary for the hierarchical regression analysis is presented in Table 2. Model 1 was a job satisfaction only model, which included both intrinsic and extrinsic job satisfaction. Model 1 was statistically significant $[\mathrm{F}(2,246)]=82.436, \mathrm{p}<.001$. The first step of the hierarchical regression model showed that intrinsic and extrinsic job satisfaction explained $39.6 \%$ of the variance in turnover intention.

Table 2: Model Summary: Hierarchical Multiple Regression Analyses on Predicting Turnover Intention

\begin{tabular}{ccccccccc}
\hline Model & $\mathrm{R}$ & $\begin{array}{c}\mathrm{R} \\
\text { Square }\end{array}$ & $\begin{array}{c}\text { Adjusted } \\
\text { R square }\end{array}$ & $\begin{array}{c}\text { R Square } \\
\text { Change }\end{array}$ & F Change & df1 & df2 & $\begin{array}{c}\text { Sig. F } \\
\text { Change }\end{array}$ \\
\hline Model 1 & $.633^{\mathrm{a}}$ & .401 & .396 & .401 & 82.436 & 2 & 246 & .000 \\
Model 2 & $.646^{\mathrm{b}}$ & .417 & .405 & .016 & 2.217 & 3 & 243 & .087 \\
Model 3 & $.647^{\mathrm{c}}$ & .419 & .400 & .002 & .268 & 3 & 240 & .848 \\
\hline
\end{tabular}

Note: a.) Predictors: (Constant), Job Satisfaction-intrinsic, Job Satisfaction-extrinsic; b.) Predictors: (Constant), Job Satisfaction-intrinsic, Job Satisfaction-extrinsic, Work engagement-vigor, dedication, and absorption; c.) Predictors: (Constant), Job Satisfaction-intrinsic, Job Satisfaction-extrinsic, Work engagement-vigor, dedication, absorption, gender, age, and years of experience; Dependent Variable: Turnover Intention

Model 2 included the predictor variables: job satisfaction (intrinsic and extrinsic) and work engagement (vigor, dedication, and absorption). When work engagement was added to the model, it was statistically non-significant $[\mathrm{F}(3,243)]=2.217, \mathrm{p}=.087$. The change in variance was $1.6 \%$.

Model 3 included job satisfaction and work engagement variables as well as demographic variables (gender, age, and years of experience). The $\mathrm{R}$ squared change indicated that work engagement and the demographic variables did not provide a substantial increase in the shared variance percent with job satisfaction. The change in the model was statistically non-significant $[\mathrm{F}(3,240)]=0.268, \mathrm{p}=0.848$ with a small change in variance of only $0.2 \%$. Adding the demographic variables into the model had an almost negligible increase in the shared variance.

The predictor variables (job satisfaction and work engagement) examined in the study had a negative relationship with turnover intention. Job satisfaction accounted for a mode- 
rate percentage (almost 40\%) of unique variation in turnover intention. In addition, findings also showed that work engagement does not moderate the relationship between job satisfaction and turnover intention. This result did not support hypothesis four.

\subsection{Discussion}

The purpose of the study was to gain a more in-depth understanding of the impact of CTE health science teachers' job satisfaction and work engagement on their intent to leave the job. Overall, there were positive and significant relationships between job satisfaction (intrinsic and extrinsic) and work engagement (vigor, dedication, and absorption). Both job satisfaction and work engagement negatively correlated with turnover intention. The more satisfied and engaged teachers are, the less likely they will leave the job.

This study confirms the findings of previous research that there is a positive relationship between job satisfaction and work engagement. Yalabik et al. (2017), in a study with banking specialists concluded that both intrinsic and extrinsic job satisfaction are linked to work engagement; emphasizing that when workers are satisfied with the job, they are fully engaged at work. Overall, intrinsic job satisfaction had a stronger positive correlation with work engagement when compared to extrinsic job satisfaction. These findings align with Hancer and George's (2003) study that the major source of satisfaction for restaurant workers was intrinsic job satisfaction. Workers need to have a certain level of achievement, competence, and autonomy to be intrinsically motivated (Gagne \& Deci, 2005). Job satisfaction impacts engagement levels therefore emphasizing the need for supervisor support, good working conditions, and a job itself that is challenging (Abraham, 2012).

Job satisfaction and work engagement negatively correlated with turnover intention, suggesting that as work engagement and job satisfaction increases, turnover intention decreases.

Mobley (1982) theorized that an employee has intent to leave a job when the worker has experienced job dissatisfaction. Research has shown that when job satisfaction increases, worker turnover and turnover intention decreases (Derby-Davis, 2014; Herzberg, 1971; Kabungaidze, Mahlatshana, \& Ngirande, 2013).

Skaalvik and Skaalvik (2011) in their study noted that when teachers have a lack of motivation, work engagement is affected. Clarke (2012) studied the retention of health science teachers in North Carolina and found that continuing education is an important tool for increasing work engagement and decreasing turnover intention. A study of career and technical education teachers found that high levels of work engagement led teachers to a greater commitment to the school district (Song, Bae, Park, \& Kim, 2013). When teachers are engaged at work there is positive employee relations, organizational stability, and retention decreases (Saks \& Gruman, 2014). However, the relationships between job satisfaction, engage- 
ment, and turnover intention of CTE health science teachers have received far less attention in spite of the shortage of health professionals.

\subsection{Implications for Research}

This study builds on the work of previous researchers by further supporting the links between job satisfaction, work engagement, and turnover intention. Turnover affects teachers, students, families, school districts, and the community. Creating strategies to retain teachers is critical to student success. Further research on teacher satisfaction, engagement, and turnover intention will not only benefit CTE health sciences but also other disciplines. Possible future studies may include qualitative research, such as, face-to-face interviews with health science teachers to gain richer perspectives. From this research, it was found that the majority $(30 \%)$ of the teachers who participated in the study had only 1 to 3 years of experience. Interviewing the teachers with more years of experience would add information critical to teacher success and retention in the health science classroom. Research including healthcare professional educators at the postsecondary levels would also build on the theories of job satisfaction, engagement, and turnover intention.

The findings of this study aligns with past research by indicating that when workers are satisfied and engaged, turnover intention decreases (Kulikowski, 2017; Skaalvik \& Skaalvik, 2011). Future research could broaden the findings of this study by adding constructs, such as leadership in school administration, various job resources, well-being, and other factors that may contribute to the satisfaction and engagement levels of teachers to aid with retention.

This study found that work engagement did not moderate the relationship between job satisfaction and turnover intention. Work engagement has not been extensively studied as moderating the relationship between job satisfaction and turnover intention. Future studies should also conduct further investigation of work engagement as a moderator variable. Because healthcare is a global concern, it would also be value-adding to replicate the study in other countries to be able to compare similarities and differences in findings.

\subsection{Implications for Practice}

This study resulted in an increased understanding of the importance of having satisfied and engaged teachers. Most teachers surveyed were satisfied with their teaching position. However, the majority of teachers participating in the study had taught for an average of one to three years. Retaining teachers after three years is a challenge since prior research shows that $25 \%$ of new teachers in the US leave the teaching profession by the third year on the job (Skaalvik \& Skaalvik, 2011). Faculty development through continuing education also leads to positive work engagement (van den Berg, Mastenbroek, Scheepers, \& Jaarsma, 2017). 
Gauging the engagement and satisfaction levels of teachers periodically can help to reduce the rate of turnover.

Derby-Davis (2014) found that factors affecting job satisfaction are noteworthy to reduce turnover intention. It is imperative for school administrators and decision makers to be knowledgeable of the influence of teacher job satisfaction and engagement on turnover intentions to be able to stabilize and increase teacher retention especially those with health science related skills that are scarce and in demand. Strategies, such as, creating positive working conditions, professional development initiatives, pay, benefits, rewards, recognition, peer and supervisor support, increased and challenging responsibilities, and a certain level of autonomy, should be encouraged to reduce attrition rates among teachers. Some amount of autonomy is necessary for teachers to be able to handle classroom situations timely (DerbyDavis, 2014).

\subsection{Limitations and Conclusion}

The study has limitations that should be considered when making recommendations. The study relied on the self-report measures which means data were collected just once, in a single US state, implying that the results may not be generalizable beyond this study. However, the constructs used for this study were appropriate for use of self-report data (Conway \& Lance, 2010). Common method bias may be a concern because the method used to measure the variables in this study were explored by the same research method (Siemsen, Roth, \& Oliveira, 2010). The survey had time constraints that may have impacted participants responses (Simon \& Goes, 2013). Additionally, participants may provide biased responses to the survey, that could have skewed the results of the study. An external variable called the participant variable depends on the respondents' individual characteristic that may affect how a participant responds to the questionnaires (Clarke, 2012), therefore influencing the results.

Healthcare is essential for the US and globally. Adequate and qualified health science teachers at the secondary level can have an impact on the healthcare professional shortage. CTE health science teachers can mentor students to not only choose the healthcare profession as an early career but to progress to more advanced levels; thereby helping to balance the supply and demand factors associated with the shortage of teachers and healthcare professionals. Educational leadership should recognize the value of healthcare professionals in the classroom by promoting factors that lead to job satisfaction and teacher engagement for the success of students and the health of communities and nation. 


\section{References}

Abraham, S. (2012). Job satisfaction as an antecedent to employee engagement. SIES Journal of Management, $8(2), 27-36$.

Advance CTE. (2017). State leaders connecting learning to work. Retrieved from https://www.careertech.org

American Association of Colleges of Nursing (AACN). (2015). Nursing faculty shortage fact sheet. Retrieved from http://www.aacn.nche.edu/media-relations/NrsgShortageFS.pdf

Bakker, A. B., Demerouti, E., \& Euwema, M. C. (2005). Job resources buffer the impact of job demands on burnout. Journal of Occupational Health Psychology, 10(2), 170-180. doi:10.1037/10768998.10.2.170

Bassett-Jones, N., \& Lloyd, G. (2005). Does Herzberg's motivation theory have staying power? Journal of Management Development, 24(10), 929-943.

Cammann, C., Fichman, M., Jenkins, D., \& Klesh, J. (1979). The Michigan organizational assessment questionnaire. Unpublished manuscript. University of Michigan: Ann Arbor.

Cangur, S., \& Ercan, I. (2015). Comparison of model fit indices used in structural equation modeling under multivariate normality. Journal of Modern Applied Statistical Methods, 14(1), 152-167.

Clarke, W. L. (2012). An inquiry into the factors that contribute to the health science teacher attrition and retention. ProQuest Dissertations and Theses (3538705).

Conway, J. M., \& Lance, C. E. (2010). What reviewers should expect from authors regarding common method bias in organizational research. Journal of Business and Psychology, 25, 325-334. doi:10.1007/s10869-010-9181-6

Derby-Davis, M. J. (2014). Predictors of nursing faculty's job satisfaction and intent to stay in academe. Journal of Professional Nursing, 30(1), 19-25. doi:19.10.1016/j.profnurs.2013.04.001

Dougherty, S. M., \& Lombardi, A. R. (2016). From vocational education to career readiness: The ongoing work of linking education and the labor market. Review of Research in Education, 40(1), 326-355. doi:10.3102/0091732X16678602

Gagne, M., \& Deci, E. L. (2005). Self-determination theory and work motivation. Journal of Organizational Behavior, 26, 331-362.

Hakanen, J. J., Bakker, A. B., \& Schaufeli, W. B. (2006). Burnout and work engagement among teachers. Journal of School Psychology, 43(6), 495-513. doi:10.1016/j.jsp.2005.11.001

Halbesleben, J. R. B., \& Wheeler, A. R. (2008). The relative roles of engagement and embeddedness in predicting job performance and intention to leave. Work \& Stress, 22(3), 242-256. doi:10.1080/02678370802383962

Hancer, M., \& George, R. T. (2003). Factor structure of the Minnesota satisfaction questionnaire short form for restaurant employees. Psychological Reports, 94(1), 357-362. doi:10.2466/pr0.94.1.357362

Harter, J. K., Schmidt, F. L., \& Hayes, T. L. (2002). Business-unit-level relationship between employee satisfaction, employee engagement, and business outcomes: A meta-analysis. Journal of Applied Psychology, 87, 268-279.

Herzberg, F. (1971). Work and the nature of man. New York, NY: World Publishing.

Herzberg, F., Mausner, B., \& Synderman, B. B. (1993). The motivation to work. New York, NY: John Wiley. 
Hooper, D., Coughlan, J., \& Mullen, M. (2008). Structural equation modelling: Guidelines for determining model fit. Electronic Journal of Business Research Methods, 6(1), 53-60.

Ingersoll, R. M. (2001). Teacher turnover and teacher shortages: An organizational analysis. American Educational Research Journal, 38(3), 499-534. doi:10.3102/00028312038003499

Judge, T. A., Weiss, H. M., Kammeyer-Mueller, J. D., \& Hulin, C. L. (2017). Job attitudes, job satisfaction, and job affect: a century of continuity and of change. Journal of Applied Psychology, 102(3), 356-374. doi:10.1037/apl0000181

Judge, T.A., \& Kammeyer-Mueller J. D. (2012). Job attitudes. Annual Review of Psychology, 63, 341367. doi:10.1146/annurev-psych-120710-100511

Kabungaidze, T., Mahlatshana, N., \& Ngirande, H. (2013). The impact of job satisfaction and some demographic variables on employee turnover intentions. International Journal of Business Administration, 4(1), 53-65.

Kahn, W. A. (1990). Psychological conditions of personal engagement and disengagement at work. The Academy of Management Journal, 33(4), 692-724. doi:10.2307/256287

Keith, Z. K. (2015). Multiple regression and beyond: An introduction to multiple regression and structural equation modeling. New York, NY: Routledge.

Kim, W. (2017). Examining mediation effects of work engagement among job resources, job performance, and turnover intention. Performance Improvement Quarterly, 29(4), 407-425. doi:10.1002/piq.21235

Kulikowski, K. (2017). Do we all agree on how to measure work engagement? Factorial validity of Utrecht work engagement scale as a standard measurement tool - A literature review. International Journal of Occupational Medicine and Environmental Health, 30(2), 161-175. doi:10.13075/ ijomeh.1896.00947

Lambert, E. G., Lynne Hogan, N., \& Barton, S. M. (2001). The impact of job satisfaction on turnover intent: A test of a structural measurement model using a national sample of workers. The Social Science Journal, 38(2), 233-250. doi:10.1016/S0362-3319(01)00110-0

Lindsay, C. A., Marks, E, \& Gorlow, L. (1967). The Herzberg Theory: A critique and reformulation. Journal of Applied Psychology, 51(4), 330-339.

Locke, E. A. (1976). The nature and causes of job satisfaction. Handbook of Industrial and Organizational Psychology, 1, 1297-1343.

Mobley, W. H. (1982). Some unanswered questions in turnover and withdrawal research. The Academy of Management Review, 71), 111-116. doi:10.5465/AMR.1982.4285493

Müller, K., Alliata, R., \& Benninghoff, F. (2009). Attracting and retaining teachers. A question of motivation. Educational Management Administration \& Leadership, 37, 574-599.

Nagele, C., Neuenschwander, P., \& Rodcharoen, P. (2018). Higher education in Switzerland: Predictors of becoming engaged in higher vocational or academic education - the role of workplace factors. International Journal for Research in Vocational Education and Training, 5(4), 264-284. doi:10.13152/IJRVET.5.4.2

Nias, J. (1981). Teacher satisfaction and dissatisfaction: Herzberg's two-factor hypothesis revisited. British Journal of Sociology of Education, 2(3), 235-246.

Nunnally, J. C., \& Bernstein, I. H. (1994). Psychometric theory(3rd ed.). New York, NY: McGraw-Hill.

Oldham, G. R., Hackman, J. R., \& Pearce, J. L. (1976). Conditions under which employees respond positively to enriched work. Journal of Applied Psychology, 61(4), 395-403. doi:10.1037//00219010.61.4.395 
Reio, T. G., Jr., \& Segredo, M. (2013). Turnover intention among middle school teachers. In M. S. Plakhotnik \& S. M. Nielsen (Eds.), Proceedings of the 12th Annual South Florida Education Research Conference (pp. 181-188). Miami: Florida International University.

Rhodes, S., \& Doering, M. (1983). An Integrated Model of Career Change. The Academy of Management Review, 8(4), 631-639.

Rowe, J. W., Fulmer, T., \& Fried, L. (2016). Preparing for better health and health care for an aging population. Jama, 316(16), 1643-1644. doi:10.1001/jama.2016.12335

Ruhland, S. K. (2001). Factors influencing the retention of secondary business teachers. Delta Pi Epsilon Journal, 43(4), 215-219.

Ruhland, S., \& Bremer, C. (2003). Perceptions of Traditionally and Alternatively Certified Career and Technical Education Teachers. Journal of Vocational Education Research, 28(3), 285-302. doi:10.5328/JVER28.3.285

Sachau, D. A. (2007). Resurrecting the Motivation-Hygiene Theory: Herzberg and the positive psychology movement. Human Resource Development Review, 6(4), 377-393.

Saks, A. M. (2006). Antecedents and consequences of employee engagement. Journal of Managerial Psychology, 21(7), 600-619. doi:10.1108/02683940610690169

Saks, A. M., \& Gruman, J. A. (2014). What do we really know about employee engagement? Human Resource Development Quarterly, 25(2), 155-182. doi:10.1002/hrdq.21187

Schaufeli, W. B., \& Bakker, A. (2004). UWES Utrecht Work Engagement Scale: Preliminary Manual. Unpublished Manuscript, Utrecht University. Retrieved from https://www.wilmarschaufeli.nl/publications/Schaufeli/Test\%20Manuals/Test_manual_UWES_English.pdf

Schaufeli, W. B., Bakker, A. B., \& Salanova, M. (2006). The measurement of work engagement with a short questionnaire: A cross-national study. Educational and Psychological Measurement, 66(4), 701-716. doi:10.1177/0013164405282471

Schaufeli, W.B., \& Salanova, M. (2007). Efficacy or inefficacy, that's the question: Burnout and work engagement, and their relationships with efficacy beliefs. Anxiety, Stress and Coping, 20, 177-196.

Schaufeli, W. B., Salanova, M., González-Romá, V., \& Bakker, A. B. (2002). The measurement of engagement and burnout: A two sample confirmatory factor analytic approach. Journal of Happiness Studies, 3(1), 71-92. doi:10.1023/A:1015630930326

Seppälä, P., Mauno, S., Feldt, T., Hakanen, J., Kinnunen, U., Tolvanen, A., \& Schaufeli, W. (2009). The construct validity of the Utrecht work engagement scale: Multisample and longitudinal evidence. Journal of Happiness Studies, 10(4), 459-481. doi:10.1007/s10902-008-9100-y

Sharp, T. P. (2008). Job satisfaction among psychiatric registered nurses in New England. Journal of Psychiatric and Mental Health Nursing, 15(5), 374-378. doi:10.1111/j.1365-2850.2007.01239.x

Siemsen, E., Roth, A., \& Oliveira, P. (2010). Common method bias in regression models with linear, quadratic, and interaction effects. Organizational Research Methods, 13(3), 456-476. doi:10.1177/1094428109351241

Simon, M. K., \& Goes, J. (2013). Assumptions, limitations, delimitations, and scope of the study. Retrieved from http://www.dissertationrecipes.com/wp-content/uploads/2011/04/Assumptions-Limitations-Delimitations-and-Scope-of-the-Study.pdf

Skaalvik, S., \& Skaalvik, E. M. (2011). Teacher job satisfaction and motivation to leave the teaching profession: Relations with school context, feeling of belonging, and emotional exhaustion. Teaching and Teacher Education, 276), 1029-1038. doi:10.1016/j.tate.2011.04.001 
Skaalvik, E. M., \& Skaalvik, S. (2014). Teacher self-efficacy and perceived autonomy: Relations with teacher engagement, job satisfaction, and emotional exhaustion. Psychological Reports, 114(1), 68-77. doi:10.2466/14.02.PR0.114k14w0

Snavely, T. M. (2016). A brief economic analysis of the looming nursing shortage in the United States. Nursing Economics, 34(2), 98-100.

Song, J. H., Bae, S. H., Park, S., \& Kim, H. K. (2013). Influential factors for knowledge creation practices of CTE teachers: Mutual impact of perceived school support, transformational leadership, and work engagement. Asia Pacific Education, 14, 467-482. doi:10.1007/s12564-013-9283-8

Song, J. H., Martens, J., McCharen, B., \& Ausburn, L. (2011). Multi-structural relationships among organizational culture, job autonomy, and CTE teacher turnover Intention. Career and Technical Education Research, 36(1), 3-26. doi:10.5328/cter36.1.3

Spector, P. E. (1997). Job satisfaction: application, assessment, causes, and consequences. Thousand Oaks, CA: Sage.

Texas Education Agency. (2017). Welcome to the Texas Education Agency. Retrieved from http://tea.texas.gov

Texas Medical Association. (2014). Health vision 2020. Retrieved from https://www.texmed.org/ uploadedFiles/Current/Advocacy/Healthy_Vision_2020/HV2020.pdf

Texas Medical Association. (2016). TMA is creating the best climate in the nation for doctors to practice. Retrieved from https://www.texmed.org/

Thibodeaux, A. K., Labat, M. B., Lee, D. E., \& Labat, C. A. (2015). The effects of leadership and highstakes testing on teacher retention. Academy of Educational Leadership Journal, 19(1), 227-237.

Tietjen, M. A., \& Myers, R. M. (1998). Motivation and job satisfaction. Management Decision, 36(4), 226-231. doi:10.1108/00251749810211027

US Bureau of Labor Statistics. (2013). Occupations with the largest projected number of job openings due to growth and replacement needs, 2012 and projected. Retrieved from https://www.bls.gov/ news.release/ecopro.t08.htm

US Bureau of Labor Statistics. (2015). Fastest growing occupations: Occupational outlook handbook. Retrieved from http://www.bls.gov/ooh/fastest-growing.htm

US Census Bureau. (2017). QuickFacts Texas. Retrieved from https://www.census.gov/quickfacts/TX

van den Berg, J. W, Mastenbroek, N. J. J. M, Scheepers, R. A., \& Jaarsma, A. D. C. (2017). Work engagement in health professions education. Medical Teacher, 39(11), 1110-1118.

Walter, R. A., \& Gray, C. K. (2002). Teacher preparation/licensure in career and technical education: A public policy analysis. Journal of Vocational Education Research, 27(1), 131-153.

Waltman, J., Bergom, I., Hollenshead, C., Miller, J., \& August, L. (2012). Factors contributing to job satisfaction and dissatisfaction among non-tenure track faculty: findings from a qualitative study. Journal of Higher Education, 83(3), 411-434.

Weiss, D. J., Dawis, R. V., \& England, G. W. (1967). Manual for the Minnesota Satisfaction Questionnaire. University of Minnesota: Industrial Relations Center. Retrieved from http://vpr.psych.umn. edu/sites/vpr.dl.umn.edu/files/monograph_xxii_-_manual_for_the_mn_satisfaction_questionnaire.pdf

Yalabik, Z. Y., Rayton, B. A., \& Rapti, A. (2017). Facets of job satisfaction and work engagement. Evidence-Based HRM, 5(3), 248-265. doi:10.1108/EBHRM-08-2015-0036 


\section{Biographical Notes}

Kathleen A. Park, PhD, is a professor and assistant department chair in Medical Laboratory Technology at Austin Community College, Texas, USA. She recently earned her PhD in Applied Technology and Performance Improvement from the University of North Texas.

Karen R. Johnson, PhD, is an assistant professor of Learning Technologies in the College of Information at the University of North Texas, USA. She conducts and publishes research on organization development, workplace learning, and performance improvement. She earned both an MA and a PhD in Work and Human Resource Education from the University of Minnesota. 